\title{
Control -Oriented Modeling and Experimental Study on Low Temperature Combustion for Diesel Engine
}

\author{
Yidong Fei, Fujun Zhang*, Tianpu Dong and Sufei Wang \\ School of Mechanical Engineering, Beijing Institute of Technology, 5 South Zhongguancun Street, Beijing, China \\ ${ }^{*}$ Corresponding author
}

\begin{abstract}
Diesel low-temperature combustion (LTC) has great potential on ultra-low emissions for internal combustion engine and has been widely researched in recent years. In order to enhance the stability of diesel LTC and improve the transient performance during low temperature combustion and conventional combustion mode switching, accurate prediction of the in-cylinder combustion state in diesel engine is required, and the control strategy should be adjusted accordingly. A controloriented combustion model which consists of the dynamic model of the intake, compression, combustion, expansion and exhaust process of diesel LTC is developed basing on in-cylinder thermodynamic cycle. The model was verified and validated with experimental data. Comparison between the calculation result and the experimental data shows that in LTC combustion mode, the maximum calculation error of indicated mean effective pressure (IMEP) is $-5.4 \%$, and the maximum calculation error of crank angle for $50 \%$ burnt fuel (CA50) is $6.6 \%$. The results prove that the state parameters of diesel engine could be predicted accurately with this model, which is fundamental for model-based control of diesel low temperature combustion.
\end{abstract}

Keywords: diesel; LTC; control-oriented; combustion model

\section{INTRODUCTION}

In order to meet the increasingly stringent emission regulations, the diesel engine LTC has been widely investigated in recent years [1-4]. By controlling the fuel injection, exhaust gas recirculation (EGR) and variable geometry exhaust gas turbocharger (VGT), improving the mixing rate of air and fuel, reduction of combustion temperature and intake oxygen concentration could be achieved, which could simultaneously lower the emission of nitrogen oxides (NOx) and soot.

However, current low-temperature combustion mode is only viable in low-speed, low-load ranges due to high EGR rate employed. In practical applications, frequent switching between traditional combustion and low temperature combustion mode is needed to meet the vehicle's power requirements. Therefore, it is necessary to accurately predict and track the changes of cylinder combustion states and adjust the control parameters accordingly in order to avoid increasing in the engine cycle fluctuations when the combustion modes are changing. Obtaining the information of the charge and combustion states in the cylinder is critical to control the combustion process with enough precision. Closed-loop real time control of the combustion can be realized by obtaining the state of combustion through direct measurement of cylinder pressure $[5,6]$. This method is mostly applied in the laboratory because of the cost and accuracy of the cylinder pressure sensor. High-precision engine simulation models based on WAVE, GT-Power and other software can obtain relatively accurate engine combustion state information, but are only available for off-line analysis. The control model based on the zerodimensional combustion model can meet the requirements of the real-time calculation and can be used to design the control strategy $[7,8]$, but fails to accurately predict the situations outside the calibration conditions. The engine quasidimensional combustion model is a mathematical model which is based on the cylinder working process, and divides the cylinder combustion chamber into several units that meet zerodimensional combustion assumptions to be calculated individually. Compared with the multi-dimensional model, it avoids solving the complex nonlinear partial differential equations while maintains the ability to predict the engine working process $[9,10]$.

This paper builds the control-oriented diesel engine combustion model based on the segment modeling method to accurately obtain the state information of the diesel engine combustion process and ensure the prediction accuracy of the model. The real-time availability of the model has been improved by selecting the appropriate calculation method and simplifying the calculation process of fuel evaporating and mixing. The model verification was carried out by using the experiment data of a 4-cylinder 4-stroke high pressure common rail LTC diesel engine.

\section{CONTROL ORIENTED MODEL}

The process in the cylinder of diesel engine is complex and varied. In order to describe the change of states in the cylinder, the pressure inside the cylinder $\mathrm{p}$, the temperature $\mathrm{T}$ and the mass $m$ with the crank angle changing within various stages of operation (such as intake, combustion, expansion, exhaust) are calculated according to the conservation of mass, energy conservation and the ideal gas equation. In this paper, the dynamic models of intake, compression, combustion, expansion and exhaust stages are constructed respectively. The intake valve opening is set to be the starting point to calculate the state parameters.

\section{A. Intake Process}

During the intake process, the intake valve is open and the fresh air enters the cylinder through the inlet. The mass flow rate entering the cylinder can be calculated by the onedimensional compressible fluid equation, as shown in (1) and 
(2).

$$
\begin{gathered}
\dot{m}_{s}=\frac{C_{D s} A_{s} p_{\text {int }}}{\sqrt{R T_{\text {int }}}} f\left(\psi_{s}\right) \\
f\left(\psi_{s}\right)=\left\{\begin{array}{cl}
\psi_{s}^{\frac{1}{\kappa}}\left\{\frac{2 \kappa}{\kappa-1}\left[1-\left(\psi_{s}\right)^{\frac{\kappa-1}{\kappa}}\right]\right\}^{\frac{1}{2}}, \psi_{s}>\left(\frac{\kappa}{\kappa+1}\right)^{\frac{\kappa}{\kappa-1}} \\
\kappa^{\frac{1}{2}}\left(\frac{2}{\kappa+1}\right)^{\frac{\kappa+1}{2(\kappa-1)}} & , \psi_{s} \leq\left(\frac{\kappa}{\kappa+1}\right)^{\frac{\kappa}{\kappa-1}}
\end{array}\right.
\end{gathered}
$$

Where $\Psi_{\mathrm{s}}=p_{\text {cyl }} / p_{\text {int }}, m_{s}$ is the intake mass flow rate; $C_{D s}, A_{s}$ are the flow coefficient and reference area of the intake valve respectively; $p_{\text {int }}, T_{\text {int }}$ are the pressure and temperature of the intake air respectively; $p_{\text {cyl }}$ is the cylinder pressure; $R$ is the gas constant; $\kappa$ is the gas specific heat capacity ratio.

According to the mass and energy conservation and ignore the influence of excess air coefficient on specific internal energy, the expression of the temperature change in the intake process can be given as:

$$
\frac{d T_{c y l}}{d \phi}=\frac{1}{m_{s} c_{v}}\left[\frac{d Q_{w}}{d \phi}-p_{c y l} \frac{d V_{c y l}}{d \phi}+\left(h_{s}-u\right) \frac{d m_{s}}{d \phi}\right]
$$

Where $T_{c y l}$ is the temperature in the cylinder; $c_{\mathrm{v}}$ is the specific heat capacity at constant volume; $Q_{w}, V_{c y l}$ are the heat transfer and volume of the cylinder respectively; $\varphi$ is the crank angle; $h_{s}$ is the specific enthalpy of working fluid at inlet; $u$ is the specific internal energy of the gas.

The gas entering the cylinder is regarded as ideal gas and the cylinder pressure can be calculated according to the ideal gas state equation, as shown in (4).

$$
p_{c y l}(\phi)=\frac{m_{s}(\phi) R T_{c y l}(\phi)}{V_{c y l}(\phi)}
$$

\section{B. Compression Process}

In the compression process, the intake and exhaust valves are closed, there is no working substance entering or exiting the cylinder, nor heat released before fuel injection. According to the energy conservation, the variation of average temperature in the compression stroke can be simplified as:

$$
\frac{d T_{c y l}}{d \phi}=\frac{1}{m_{s} c_{v}}\left(\frac{d Q_{w}}{d \phi}-p_{c y l} \frac{d V_{c y l}}{d \phi}\right)
$$

Assuming that the compression process of the diesel engine is an adiabatic process, according to the first law of thermodynamics, the cylinder pressure is calculated according to the volume change rate and pressure of the adjacent step. The expression is shown as follows:

$$
p_{c y l}(\phi)=p_{c y l}(\phi-1)\left[\frac{V_{c y l}(\phi-1)}{V_{c y l}(\phi)}\right]^{\kappa}
$$

\section{Combustion Process}

In the combustion process, the intake and exhaust valves are closed. Fuel is injected into the cylinder, and undergoes the process of atomizing, evaporating, mixing, burning, etc. The process continues until all fuel is burned out and is usually divided into the ignition delay period, the pre-mixed combustion period, the diffusion combustion period and the post combustion period. The proportion of premixed combustion is determined by the amount of mixed gas prepared during the ignition delay period [11]. In order to reflect the effect of intake dilution on the ignition delay in high EGR rate, this paper chooses (7) to calculate the period of ignition delay [12].

$$
\begin{aligned}
& \tau_{I D}=C_{I D}\left(\left[O_{2}\right]_{i n}+\left[F_{O}\right]_{f l}\right)^{-0.1} p_{c y l}^{-1.02} \times \ldots \\
& \times \exp \left(\frac{2100[71.3 /(C N+25)]}{T_{c y l}}\right)
\end{aligned}
$$

Where, $\tau_{I D}$ is the period of ignition delay; $C_{I D}$ is the coefficient of the ignition delay period; $\left[\mathrm{O}_{2}\right]_{i n}$ is the oxygen concentration of intake air. $\left[F_{\mathrm{O}}\right]_{f l}$ is the oxygen concentration of fuel. $C N$ is the octane number of fuel.

Assuming that the combustion of evaporated fuel is complete, the combustion rate of fuel in the premixed combustion stage is limited by three aspects: fuel evaporation rate, air entrainment rate and premixed chemical reaction rate, which can be expressed as follows:

$$
\frac{d m_{f b}}{d t}=A_{p r e} \rho_{m i x}^{2} x_{f v} x_{O_{2}}^{5} \exp \left(\frac{-12000}{T_{b u l k}}\right) V_{b u l k}
$$

Where $m_{f b}$ is the mass of burned fuel; $A_{\text {pre }}$ is the model coefficient of the premixed combustion period; $\rho_{\text {mix }}$ is the density of mixed gas; $x_{f v}$ is the percentage of the fuel evaporation; $x_{\mathrm{O} 2}$ is the oxygen concentration of the environment; $T_{\text {bulk }}, V_{\text {bulk }}$ are the current temperature and volume of the spray zone respectively.

In the stage of diffusion combustion, the combustion rate of the fuel is mainly determined by the amount of the entrained air and oxygen concentration. When the oxygen concentration is sufficient, the combustion rate is determined by the fuel evaporation rate; while the oxygen concentration is insufficient, the combustion rate is determined by the air entrapment rate, as shown in (9).

$$
\frac{d m_{f b}}{d t}=A_{d i f f} \min \left[m_{f v}, \frac{m_{O_{2}}}{\left(O_{2} / f\right)_{s t}}\right]
$$

Where $A_{\text {diff }}$ is the model coefficient of the diffusion combustion period; $m_{\mathrm{O} 2}$ is the oxygen concentration of the entrained air; $\left(\mathrm{O}_{2} / f\right)_{\text {st }}$ is the stoichiometric ratio of oxygen to 
fuel.

In the combustion process, both the burned and unburned mixture are assumed as the ideal gases. According to the energy conservation equation, the gas temperature of the burned and unburned zones is calculated separately, as shown in (10) and (11).

$$
\begin{gathered}
\frac{d\left(m_{\text {bulk }} u_{\text {bulk }}\right)}{d t}=\frac{d Q_{c, b u l k}}{d t}-p_{c y l} \frac{d V_{\text {bulk }}}{d t}-\frac{d Q_{w, b u l k}}{d t}+\ldots \\
+c_{p, a i r} T_{\text {air }} \frac{d m_{a, e}}{d t}+c_{p, f l} T_{f l} \frac{d m_{f l}}{d t} \\
\frac{d\left(m_{\text {air }} u_{\text {air }}\right)}{d t}=-p_{c y l} \frac{d V_{\text {air }}}{d t}-\frac{d Q_{w, a i r}}{d t}+\ldots \\
+c_{p, a i r} T_{\text {air }} \frac{d m_{\text {air }}}{d t}
\end{gathered}
$$

Where $m_{b u l k}$ is the mixture mass of the spray area; $m_{a i r}$ is the air mass of the unburned area; $u_{b u l k}$ is the mixture specific internal energy of the spray area; $u_{\text {air }}$ is the gas specific internal energy of the unburned area; $Q_{c, \text { bulk }}$ is the heat output of the burned mixture; $Q_{w, b u l k}$ is the heat dissipating capacity of the spray area; $Q_{w, \text { air }}$ is the heat dissipating capacity of the unburned area; $c_{p, a i r}$ is the heat capacity at constant pressure of the air in cylinder; $T_{a i r}$ is the temperature of the air in cylinder; $c_{p, f l}$ is the heat capacity at constant pressure of the fuel in cylinder; $T_{f l}$ is the temperature of the fuel.

\section{Expansion Process}

The expansion process is similar to the compression process. The pressure and temperature in cylinder can be calculated by using the same calculation method as show in (5) and (6).

\section{E. Exhaust Process}

In the exhaust process, the exhaust valve is open, and there is no combustion heat release nor fresh working substance flow into the cylinder. According to the mass and energy conservation equation, the temperature in the cylinder can be expressed by (12).

$$
\frac{d T_{c y l}}{d \phi}=\frac{1}{m_{e} c_{v}}\left[\frac{d Q_{w}}{d \phi}-p_{c y l} \frac{d V_{c y l}}{d \phi}+\left(h_{e}-u\right) \frac{d m_{e}}{d \phi}\right]
$$

Where $m_{e}$ is the mass of exhaust; $h_{e}$ is the specific enthalpy of the working substance at the exhaust valve. The calculation method of the exhaust mass flow rate and the cylinder pressure are similar to the intake process, like (2) and (4).

\section{Model Verification}

In this paper, the control oriented combustion model is verified by using the experimental data and simulation data. The bench test of engine was carried out on an electronically controlled high pressure common rail diesel engine with a modified EGR system. The engine simulation model was developed by GT-Power software, in which the DI-Jet quasidimensional combustion model is selected.

\section{A. Model Verification Method}

In the process of model verification, firstly, the output results of the simulation model were checked and verified by the cylinder pressure, the heat release rate, the fuel injection rule and the intake state at the set test point. Then, the output of the simulation model is used to calibrate the model coefficients of each process in the control model, such as the valve flow coefficient during the intake and exhaust process. At the same time, the parameters in the combustion process and the heat transfer coefficient are calibrated by the tested cylinder pressure and heat release rate and others. The control model is modeled by using MATLAB / Simulink software, downloaded to the dSPACE MircoAutoBox real-time system. The calculation step in the combustion process is $0.4^{\circ} \mathrm{CA}$, while in other processes the calculation step is $6^{\circ} \mathrm{CA}$ due to the lack of dramatic changes in energy and mass. The total cycle calculation time is $43 \mathrm{~ms}$, which can ensure that the characteristics of combustion are obtained and the control parameters are adjusted in time at the speed of $2500 \mathrm{r} / \mathrm{min}$.

\section{B. Engine Test System and Test Scheme}

The schematic of diesel engine test bench is shown in Figure 1 and the specifications of the test engine are listed in Table 1. For the high pressure EGR system, the EGR gas is introduced to the intake manifold by using the electronic controlled EGR device and electronic throttle. When the bench is calibrated, the EGR rate is calculated with the ECM's EGR 5230 Analyzer. A Bosch ECU with ETK unit is used as the engine controller unit. Injection strategy calibration is done with INCA. A Kistler 6056A sensor is installed in cylinder to trace real-time cylinder pressure during combustion. The DEWETRON 5000 combustion analysis system is used to sample cylinder pressure and estimate combustion state parameters. The sampling interval is $0.2^{\circ} \mathrm{CA}$ and the combustion characteristic parameters are calculated by 100 cycles' data at every steady state point.

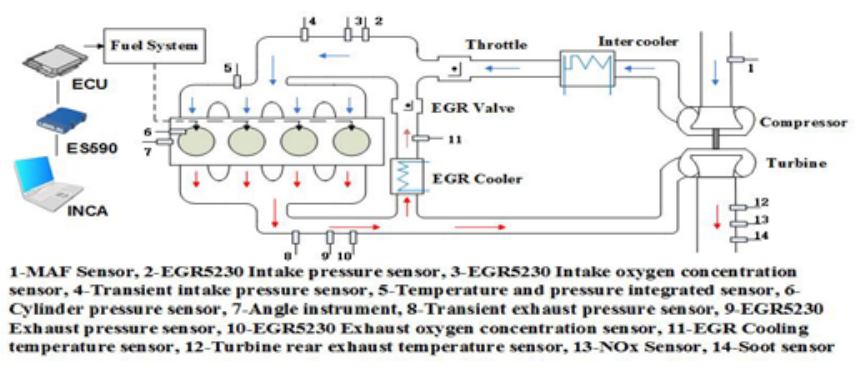

FIGURE I. THE SCHEMATIC OF DIESEL ENGINE TESTING BENCH

TABLE I. ENGINE SPECIFICATIONS

\begin{tabular}{|c|c|}
\hline Parameter & Value/Unit \\
\hline Bore & $92 \mathrm{~mm}$ \\
\hline Stroke & $94 \mathrm{~mm}$ \\
\hline Connecting rod length & $159 \mathrm{~mm}$ \\
\hline Displacement & $2.499 \mathrm{~L}$ \\
\hline Compression ratio & 17.5 \\
\hline Maximum power & $105 \mathrm{~kW} @, 4000 \mathrm{rpm}$ \\
\hline Maximum torque & $340 \mathrm{~N} . \mathrm{m} @, 2000 \mathrm{rpm}$ \\
\hline
\end{tabular}


During the test, the engine speed is $1500 \mathrm{rpm}$ and single injection strategy is used. The quantity of fuel injection is $15 \mathrm{mg}$ - (cycle - cylinder)-1; The fuel injection pressure is $75 \mathrm{MPa}$; The intake temperature is controlled at $30{ }^{\circ} \mathrm{C}$; The fuel temperature is maintained at $35^{\circ} \mathrm{C}$; The coolant temperature is set to $85^{\circ} \mathrm{C}$; In order to verify the calculation result of the combustion model both in conventional combustion region and in low temperature combustion region. The EGR rate and the injection timing are set as shown in Table 2.

TABLE II. EXPERIMENTAL PARAMETERS OF EGR AND INJECTION TIMING

\begin{tabular}{|c|c|}
\hline EGR rate/\% & Injection Timing/ ${ }^{\mathbf{0}}$ CA ATDC \\
\hline 0 & -7 \\
\hline 25 & -7 \\
\hline 55 & -7 \\
\hline 55 & -11 \\
\hline 55 & -14 \\
\hline
\end{tabular}

IV. MODEL VALIDATION

In order to verify the computational accuracy and predictive ability of the control model in the conventional combustion and low temperature combustion, the results of the control model and bench test are compared in the aspects of the cylinder pressure, heat release rate, indicated mean effective pressure (IMEP) and combustion phase under two combustion modes, which was switched by changing EGR rate. The influence of fuel injection phase on combustion during low temperature combustion is also compared.

\section{A. The Influence of EGR Rate}

When the exhaust gas is reintroduced into the cylinder, the intake oxygen concentration is reduced and the rate of combustion reaction drops. There are many triatomic molecules in the recycled gas, such as $\mathrm{CO}_{2}$ and $\mathrm{H}_{2} \mathrm{O}$, which increase the intake specific heat capacity and reduce the temperature during compression and combustion processes. The intermediate within the exhaust produced in the last cycle can influence the combustion reaction process in next cycle. Especially, when the engine switches into the low temperature combustion mode from conventional combustion mode (injection advance angle is $-7^{\circ} \mathrm{CA}$ ATDC), the period of ignition delay is extended from $8.3^{\circ} \mathrm{CA}$ to $15^{\circ} \mathrm{CA}$, increasing by $81 \%$, because of the high EGR rate. The decline of intake oxygen concentration results in a slower combustion rate, a delayed combustion phase and a longer duration of combustion. In the adiabatic compression process, the cylinder pressure will be decreased at the same crank angle as EGR rate rises. The overly delayed combustion phase leads to lower combustion thermal efficiency, larger cycle fluctuation and even misfiring, as shown in Figure 2.

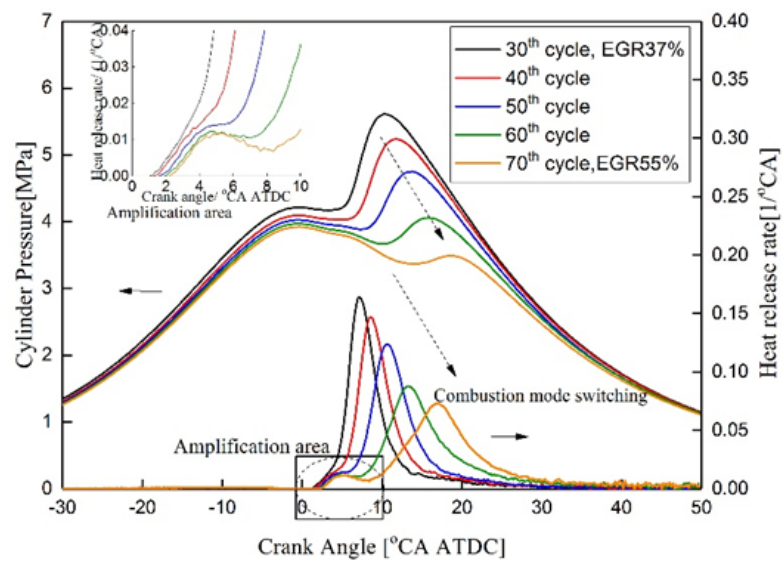

FIGURE II. CYLINDER PRESSURE AND HEAT RELEASE RATE CURVES WHEN COMBUSTION MODE SWITCHING

Figure 3 shows the comparison of cylinder pressure and instantaneous heat release rate between the experiment and quasi-dimensional combustion control model at different EGR rate $(0 \%, 25 \%, 55 \%)$ respectively. As can be seen from the figures, the calculated cylinder pressure curves are basically the same as the measured cylinder pressure curves, and the differences in both the maximum cylinder pressure and the corresponding crank angle are small, with errors less than $2 \%$. Neither is there much difference in the instantaneous heat release rate curve.

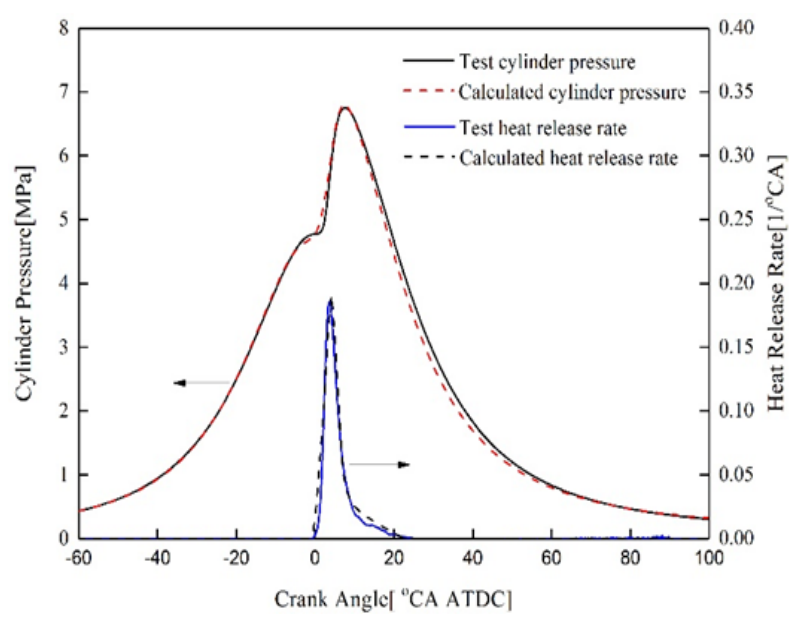

(a) $0 \%$ EGR rate 


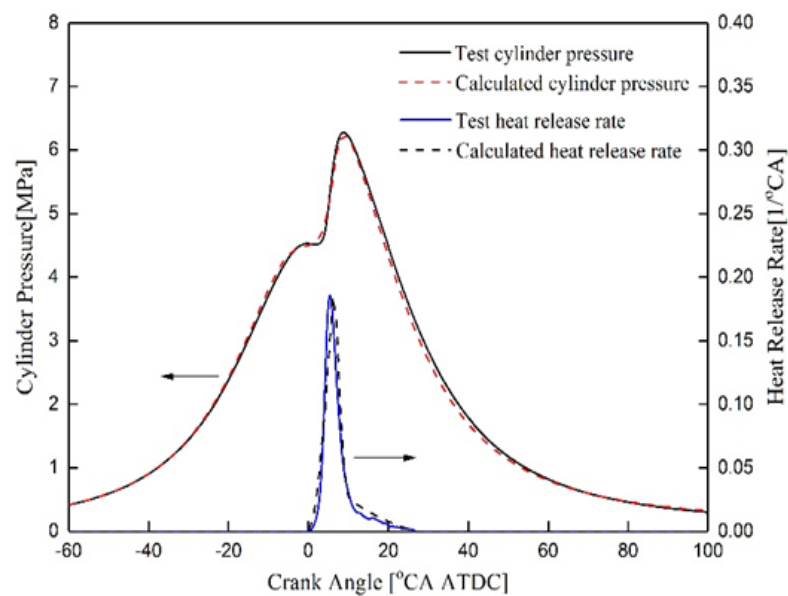

(b) $25 \%$ EGR rate

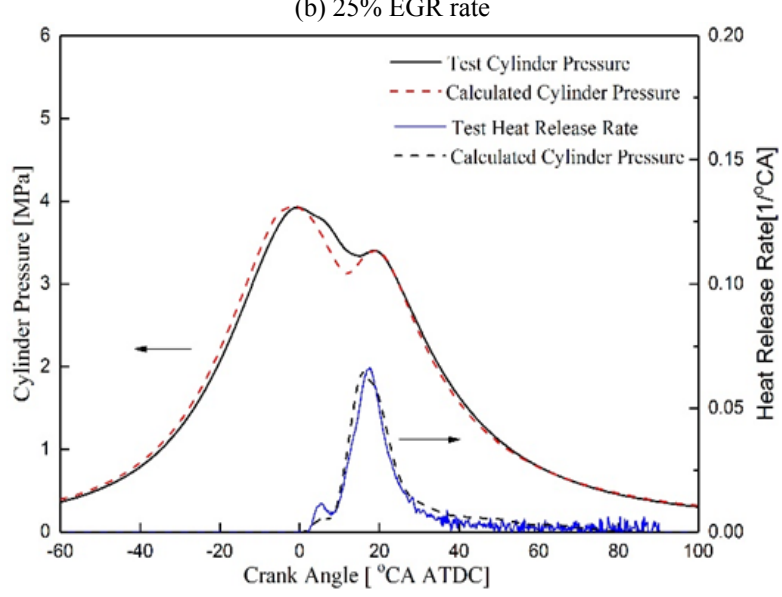

(c) $55 \%$ EGR rate

FIGURE III. COMPARISON OF CYLINDER PRESSURE AND HEAT RELEASE RATE CURVES AT DIFFERENT EGR RATE

Table 3 lists some indicators of combustion state at different EGR rate, such as the maximum cylinder pressure $\left(p_{c y l \max }\right)$ and the corresponding crank angle $\left(\varphi_{p \max }\right)$, the indicated mean effective pressure (IMEP), the period of ignition delay $\left(\tau_{I D}\right)$, and the crank angle at the half heat release $(C A 50)$. Comparing the test results and the control model calculation results, the maximum error of $I M E P$ is $1.6 \%$, and the maximum error of $C A 50$ is $3.4 \%$.

TABLE III. Comparison of results at different EGR rate

(a) $0 \%$ EGR rate

\begin{tabular}{|c|c|c|c|}
\hline State index & Experimental result & Simulation result & error $/ \%$ \\
\hline $\boldsymbol{p}_{\text {cvlmax }} / \mathbf{M P a}$ & 6.96 & 7.04 & 0.8 \\
\hline $\boldsymbol{\varphi}_{\text {max }} /{ }^{\circ} \mathbf{C A}$ & 7.20 & 7.15 & -0.7 \\
\hline $\boldsymbol{I M E P} / \mathbf{M P a}$ & 0.394 & 0.397 & 0.8 \\
\hline$\tau_{\boldsymbol{D}} /{ }^{\circ} \mathbf{C A}$ & 6.8 & 6.8 & 0 \\
\hline $\boldsymbol{C A 5 0} / \mathbf{C A}$ & 3.92 & 4.04 & 3.1 \\
\hline
\end{tabular}

(b) $25 \%$ EGR rate

\begin{tabular}{|c|c|c|c|}
\hline State index & Experimental result & Simulation result & error/\% \\
\hline $\boldsymbol{p}_{\text {cvlmax }}$ & 6.75 & 6.78 & 0.4 \\
\hline $\boldsymbol{\varphi}_{\text {pmax }} /{ }^{\circ} \mathbf{C A}$ & 7.61 & 7.56 & -0.7 \\
\hline $\boldsymbol{I M E P} / \mathbf{M P a}$ & 0.390 & 0.393 & 0.8 \\
\hline$\tau_{\boldsymbol{n}} / \mathbf{C A}$ & 6.9 & 6.8 & -1.4 \\
\hline $\boldsymbol{C A 5 0} / \mathbf{C A}$ & 4.86 & 5.00 & 2.9 \\
\hline
\end{tabular}

(c) $55 \%$ EGR rate

\begin{tabular}{|c|c|c|c|}
\hline State index & Experimental result & Simulation result & error $/ \%$ \\
\hline $\boldsymbol{p}_{\text {cvlmax }}$ & 5.75 & 5.73 & -0.3 \\
\hline $\boldsymbol{\varphi}_{\text {pmax }} /{ }^{\circ} \mathbf{C A}$ & 10.6 & 10.8 & 1.9 \\
\hline $\boldsymbol{I M E P} / \mathbf{M P a}$ & 0.375 & 0.369 & -1.6 \\
\hline$\tau_{\text {In }} / \mathbf{C A}$ & 8.3 & 8.1 & -2.4 \\
\hline $\boldsymbol{C A 5 0} / \mathbf{C A}$ & 7.63 & 7.89 & 3.4 \\
\hline
\end{tabular}

\section{B. The Effects of Fuel Injection Phase}

Figure 4 shows the cylinder pressure and heat release curves at different injection timing in low temperature region. With the advance of the injection phase, the maximum cylinder pressure and the peak heat release rate are increased, the combustion duration is shortened and the combustion stability is improved.

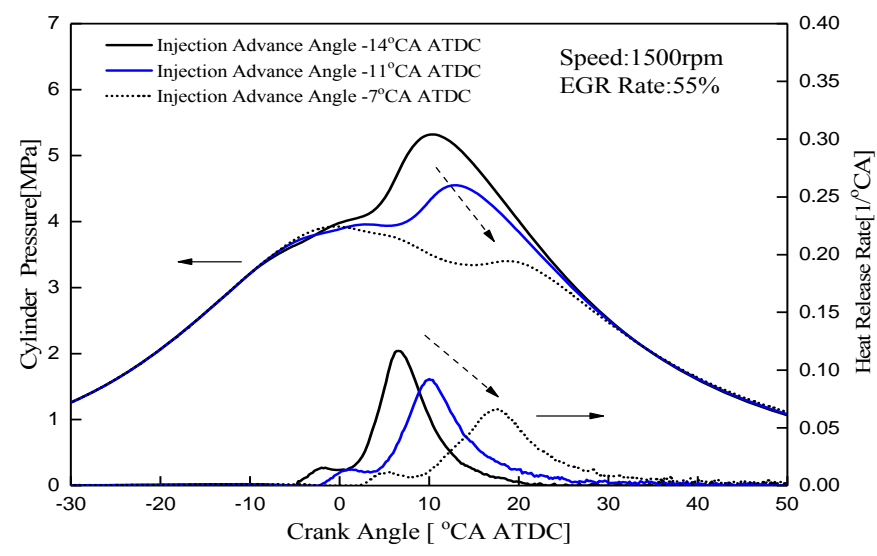

FIGURE IV. CYLINDER PRESSURE AND HEAT RELEASE RATE CURVES AT DIFFERENT INJECTION TIMING IN LOW TEMPERATURE MODE

Figures 5 indicates the comparison of cylinder pressure and instantaneous heat release rate between the experiment and quasi-dimensional combustion control model at different injection timing respectively. It can be seen from the figures that the cylinder pressure curves are basically the same and the differences in the maximum cylinder pressure and its corresponding phase are small when the injection advance angle from $-7^{\circ} \mathrm{CA}$ ATDC to $-14^{\circ} \mathrm{CA}$ ATDC. But the error of cylinder pressure nearby the ignition point is increasing with the fuel injection phase lag, the main reason being that the cylinder undergoes an extremely complex chemical exothermic reaction at the initial stage of the low-temperature combustion [13] so that the model can't reflect the actual situation in the cylinder.

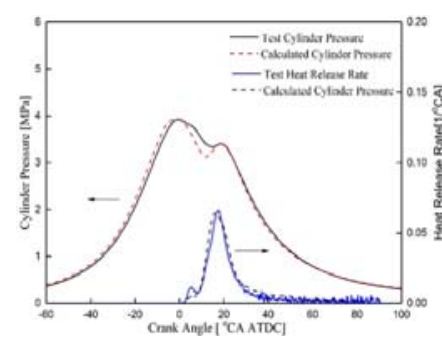

(a) Injection timing at $-7^{\circ} \mathrm{CA}$ ATDC (b) Injection timing at $-11^{\circ} \mathrm{CA}$ ATDC

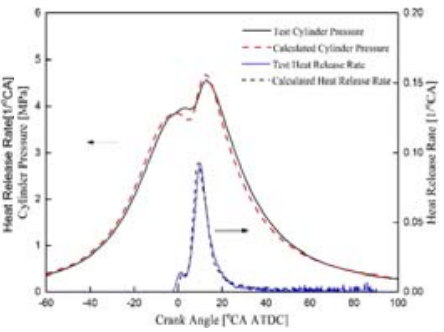




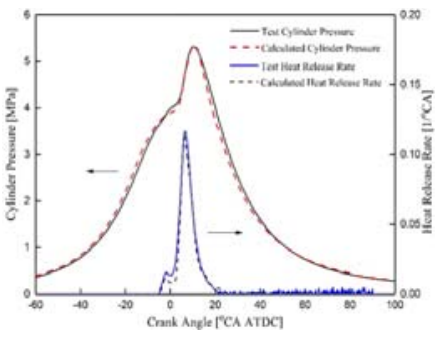

(c) Injection timing at $-14^{\circ} \mathrm{CA}$ ATDC

\section{FIGURE V. CYLINDER PRESSURE AND HEAT RELEASE RATE CURVES AT DIFFERENT INJECTION TIMING IN LOW TEMPERATURE}

Table 4 lists the comparison of some indicators of combustion state between the test and the control model at different injection advance angles, such as $p_{c y l m a x}, \varphi_{p \max } I M E P$, $\tau_{I D}$ and CA50. Among these, the maximum error of IMEP is $5.4 \%$, and the maximum error of CA50 is $6.6 \%$.

\section{TABLE IV. COMPARISON OF RESULTS AT DIFFERENT INJECTION TIMING}

(A) INJECTION TIMING AT $-7^{\circ} \mathrm{CA}$ ATDC

\begin{tabular}{|c|c|c|c|}
\hline State index & Experimental result & Simulation result & error/\% \\
\hline $\boldsymbol{p}_{\text {cvlmax }} / \mathbf{M P a}$ & 0.39 & 0.39 & 0 \\
\hline $\boldsymbol{\varphi}_{\text {mmax }} /{ }^{\circ} \mathbf{C A}$ & 0 & 0 & 0 \\
\hline $\boldsymbol{I M E P} / \mathbf{M P a}$ & 0.335 & 0.317 & -5.4 \\
\hline$\tau_{\text {ID }} /{ }^{\circ} \mathbf{C A}$ & 15.0 & 14.5 & -3.3 \\
\hline $\boldsymbol{C A 5 0} / \mathbf{C A}$ & 19.41 & 18.12 & -6.6 \\
\hline
\end{tabular}

(B) INJECTION TIMING AT $-11^{\circ} \mathrm{CA}$ ATDC

\begin{tabular}{|c|c|c|c|}
\hline State index & Experimental result & Simulation result & error/\% \\
\hline $\boldsymbol{p}_{\text {cvlmax }} / \mathbf{M P a}$ & 0.47 & 0.48 & 2.1 \\
\hline $\boldsymbol{\varphi}_{\text {pmax }} /{ }^{\circ} \mathbf{C A}$ & 13.27 & 13.14 & 1 \\
\hline $\boldsymbol{I M E P} / \mathbf{M P a}$ & 0.354 & 0.370 & 4.5 \\
\hline$\tau_{\boldsymbol{D}} /{ }^{\circ} \mathbf{C A}$ & 14.4 & 13.8 & -4.2 \\
\hline $\boldsymbol{C A 5 0 / \mathbf { C A }}$ & 10.41 & 9.94 & -4.5 \\
\hline
\end{tabular}

(C) INJECTION TIMING AT $-14^{\circ} \mathrm{CA}$ ATDC

\begin{tabular}{|c|c|c|c|}
\hline State index & Experimental result & Simulation result & error/\% \\
\hline $\boldsymbol{p}_{\text {cvlmax }} / \mathbf{M P a}$ & 0.52 & 0.53 & 1.9 \\
$\boldsymbol{\varphi}_{\text {mmax }} /{ }^{\circ} \mathbf{C A}$ & 10.82 & 10.94 & 1.1 \\
\hline $\boldsymbol{I M E P} / \mathrm{MPa}$ & 0.356 & 0.364 & 2.2 \\
\hline$\tau_{\text {II }} /{ }^{\circ} \mathbf{C A}$ & 14.3 & 13.8 & -3.5 \\
\hline $\boldsymbol{C A 5 0} / \mathbf{C A}$ & 7.18 & 7.45 & 3.8 \\
\hline
\end{tabular}

\section{CONCLUSION}

Based on the droplet evaporation quasi-dimensional combustion model, a diesel engine combustion control model is designed and the model validation was done by using the experimental data which were obtained from a 4-cylinder 4stroke high pressure common rail diesel engine working at 1500rpm, 25\% load, low temperature combustion mode and conventional combustion mode.

(1) The quasi-dimensional combustion control model can predict the combustion characteristic parameters in the cylinder. Compared with the test data, it has a good prediction accuracy. The calculated results are almost consistent with the experimental results. In the low temperature combustion mode, the maximum error of IMEP is $-5.4 \%$, and the maximum error of CA50 is $6.6 \%$. In the conventional combustion mode, the maximum error of IMEP is $1.6 \%$, and the maximum error of

\section{CA50 is $3.4 \%$}

(2) Through the simplification of the model, the rapid prototyping platform cyclic calculation results is $43 \mathrm{~ms}$, which can ensure that the control parameters can be timely adjusted at the speed of 2500rpm, so the combustion stability can be maintained.

(3) The model coefficients in the control model are calibrated by using the experiment and simulation data. At the same time, the influence of intake dilution on the calculation of the ignition delay period, the pre-mixed and diffusion combustion processes in the low temperature combustion mode is also considered when the EGR rate is high.

\section{ACKNOWLEDGMENT}

This work was supported by Fundamental Science on Vehicular Power System Laboratory, Beijing Institute of Technology. And it is grateful to Doctor Zhigang Chai for his help.

\section{REFERENCES}

[1] S. Gan, Ng. H., and K. Pang, "Homogeneous Charge Compression Ignition (HCCI) Combustion: Implementation and Effects on Pollutants in Direct Injection Diesel Engines," Applied Energy, vol 88, pp. 559-567, 2011.

[2] S. Kimura, H. Ogawa, Y. Matsui, and Y. Enomoto, "An Experimental Analysis of Low-Temperature and Premixed Combustion for Simultaneous Reduction of NOx and Particulate Emissions in Direct Injection Diesel Engines, " International Journal of Engine Research, vol 3,pp.249-259, 2002.

[3] B. Yang, S. Li, Z. Zheng and M. F.Yao, "A Comparative Study on Different Dual-Fuel Combustion Modes Fuelled with Gasoline and Diesel," SAE Technical Paper. No.2012-01-0694, 2012.

[4] Q. Zhang, M. Yao, Z. Zheng and J. Xu, "Effects of Intake Pressure on Diesel Low Temperature Combustion," Chinese Transactions of CSICE. 30(5):385-389, 2012

[5] F. Yang, Y. Yang, M. OuYang and L.Chen, "Research on Close-Loop Control Strategy of Diesel Engine Based on In-Cylinder Pressure," Chinese Transactions of CSICE, vol 30, pp.172-178, 2012.

[6] C. Fang, G. Gao and F. Yang, X. Xiang, "Development of ControlOriented in-Cylinder Combustion Analysis Unit for Diesel Engine," Chinese Internal Combustion Engine Engineering, vol 35, pp.51-56, 2014.

[7] S. Zhang, G.M. Zhu and Z. Sun, "A Control-Oriented Charge Mixing and Two-Zone HCCI Combustion Model," IEEE Transactions on Vehicular Technology, vol 63, pp.1079-1090, 2014.

[8] S. Klein, R.Savelsberg, F.Xia, and D. Guse, "Engine in the Loop: Closed Loop Test Bench Control with Real-Time Simulation" SAE International Journal of Commercial Vehicles, vol.10.pp. 95-105,2017.

[9] M.Ates, R.Matthews, and M.Hall, "A Full-Cycle Multi-Zone QuasiDimensional Direct Injection Diesel Engine Model Based on a Conceptual Model Developed from Imaging Experiments," $S A E$ Technical Paper, No 2017-01-0537, 2017.

[10] W. Sun, S.Shi, K.Zhao, and Y.Yue, "A Phenomenological Combustion Model for a D.I Diesel Engine and Its Application,"Chinese Transactions of CSICE, vol 9, pp. 213-220, 1991.

[11] M. Zheng, M. Mulenga, G. Reader and M.Wang, "Biodiesel Engine Performance and Emission in Low Temperature Combustion," Fuel, vol 87, pp.714-722, 2008.

[12] U. Asad and M. Zheng "Exhaust Gas Recirculation for Advanced Diesel Combustion Cycles," Applied Energy, vol 123, pp. 242-252, 2014.

[13] S. Tanaka, F. Ayala, J. Keck, and J. Heywood, "Two-Stage Ignition in HCCI Combustion and HCCI Control by Fuels and Additives," Combustion and Flame, vol 132,pp. 219-239, 2003. 